\title{
An arterial faceoff classic: The "T off" between the right internal thoracic and radial arteries
}

\author{
Saswata Deb, MD, and Stephen E. Fremes, MD
}

\footnotetext{
From the Schulich Heart Centre, Sunnybrook Health Sciences Centre, and the Toronto Ontario Institute of Health Policy Management and Evaluation, University of Toronto, Toronto, Ontario, Canada. Disclosures: Authors have nothing to disclose with regard to commercial support.

Received for publication Dec 20, 2015; accepted for publication Dec 21, 2015; available ahead of print Jan 29, 2016.

Address for reprints: Stephen E. Fremes, MD, Bernard S. Goldman Chair in Cardiovascular Surgery, University of Toronto, Schulich Heart Centre, Sunnybrook Health Sciences Center, 2075 Bayview Ave, Room H405, Toronto, Ontario M4N 3M5, Canada (E-mail: stephen.fremes@sunnybrook.ca).

J Thorac Cardiovasc Surg 2016;151:1320-2

$0022-5223 / \$ 36.00$

Copyright $(2) 2016$ by The American Association for Thoracic Surgery

http://dx.doi.org/10.1016/j.jtcvs.2015.12.046
}

In this issue of the Journal, Pevni and colleagues ${ }^{1}$ report their single-center retrospective observational study comparing composite bilateral internal thoracic artery grafting (T-BITA) grafting $(\mathrm{n}=1329)$ with composite single left internal thoracic artery and radial artery (RA) grafting (T-SITA-RA; $\mathrm{n}=389$ ) in patients undergoing left-sided multivessel coronary artery bypass grafting surgery (CABG) from 1996 to 2010. They performed multiple adjusted analyses, including propensity techniques, and concluded that long-term outcomes of T-SITA-RA were not inferior to those of T-BITA (10-year Kaplan-Meier survivals T-BITA, $61.6 \%$; T-SITA-RA, $64.9 \% ; P=.65)$. In the last decade, there has been growing support in the literature for arterial revascularization in $\mathrm{CABG}^{2-4}$ The recently published Society of Thoracic Surgeons practice guidelines on arterial revascularization ${ }^{5}$ recommended a second arterial graft, namely either a right internal thoracic artery (RITA) or RA graft (class of recommendation IIa, level of evidence B), according to individual patient characteristics. The key question that Pevni and colleagues ${ }^{1}$ are attempting to answer in their article is whether the RITA or RA is preferred as the second arterial conduit.

Most of the data comparing these arterial conduits have been derived from observational studies, and the results have been mixed. ${ }^{6-9}$ There are only 2 RCTs to our knowledge that have addressed this issue. ${ }^{10,11}$ The first was performed in a group of 120 patients with previous coronary stenting and found similar results for the RITA and RA grafts (and both better than the results with saphenous vein grafts). ${ }^{10}$ The second is the Radial Artery Patency and Clinical Outcomes study (RAPCO), ${ }^{11}$ interim results of which have been published, showing similar event-free survivals and graft patencies in the RITA and RA cohorts, although numerically better in the RA group. Ten-year results are pending.

Furthermore, in the study of Pevni and colleagues, ${ }^{1}$ all patients had composite arterial grafting. Composite arterial grafting with the left internal thoracic artery as inflow has

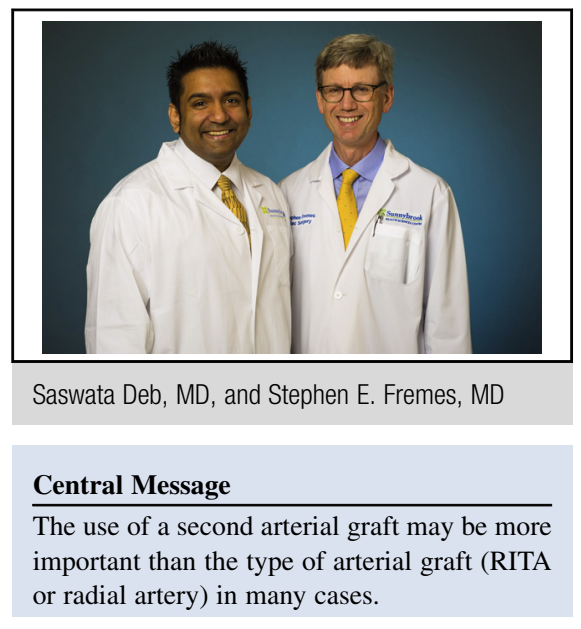

See Article page 1311.

become more popular. ${ }^{12}$ This strategy has many advantages, including efficient use of limited arterial conduits and decrease in aortic manipulation and thereby stroke ${ }^{13}$; disadvantages of this strategy include the possibility of steal from the second graft connected to the left internal thoracic artery and competitive flow from the native coronary artery. ${ }^{13} \mathrm{Kim}$ and associates ${ }^{14}$ (SAVE RITA trial) reported excellent composite RITA patency at 1-year $(97.1 \%)$. Glineur and coworkers ${ }^{15}$ investigated the causes of nonfunctioning composite RITAs and reported that the function of a Y-RITA is much better when grafted to branches of the circumflex coronary artery than the right coronary artery. Furthermore, Gaudino and colleagues ${ }^{16}$ showed that the RA is more vulnerable to the effects of competitive flow when anastomosed to the internal thoracic artery than to the aorta.

Pevni and colleagues ${ }^{1}$ are to be congratulated on such a high rate of arterial revascularization in their institution; however, there are a number of points worth discussing. First, there were many important baseline differences between the T-BITA and T-SITA-RA group. Of the 3165 patients who underwent left-sided arterial revascularization, the great majority of the entire population $(87.7 \%)$ and the T-graft cohort specifically $(77.4 \%)$ had bilateral ITA grafting; Pevni and colleagues ${ }^{1}$ mention that conduit choice was mainly by surgeon preference, but it is unclear whether additional factors like coronary anatomy and severity of target vessel disease were considered. The latter has been shown to be an important predictor of late radial patency. ${ }^{17}$ Although the prevalence of some individual risk variables was greater in the RITA cohort, ${ }^{1}$ the RA cohort patients 
were older and more likely female, and their mean euroSCORE was higher, suggesting that the RA was used preferentially in higher risk patients. There were also significant intraoperative differences in the matched comparison between the T-BITA and T-SITA-RA cohorts; the T-SITARA cohort underwent a higher proportion of off-pump CABG procedures $(42.2 \%$ vs $16 \% ; P<.001)$ and had fewer total grafts than the BITA cohort $(72.4 \%$ vs $79.5 \%$; $P=.03$ ). The latter is likely because of the use of more sequential grafts with the RA to both the circumflex and right coronary artery territories. In addition, it was not until 1999 that the center started performing T-SITA-RA revascularization, which may have introduced temporal and practice-based biases.

Finally, there were copious baseline differences between the T-BITA and T-SITA-RA cohorts in this study; Pevni and colleagues ${ }^{1}$ attempted to adjust for the large selection bias with propensity techniques. In addition to the fact that propensity techniques cannot adjust for unknown confounders, one assumption of such techniques is that all variables that affect treatment assignment and outcome, even if only moderately, should be measured and included. ${ }^{18}$ In this study, intraoperative covariates were not included (even though it was known they were unbalanced) in the generation of the propensity model, which could explain the imbalance between the matched groups with respect to these variables. Moreover, their match resulted in 268 pairs; given that there were only 389 patients in the T-SITA-RA group, this represents more than a $30 \%$ loss from the population of interest. Perhaps another propensity technique would have been preferable, because such a loss could result in decreased generalizability and accuracy of the results. ${ }^{18}$ It is also worth noting that Pevni and colleagues ${ }^{1}$ applied multiple propensity techniques (matching with propensity scores, covariate adjustment, and stratification) along with multiple logistic regression techniques (stepwise regression with forced variables) for modeling. Although having a sensitivity analysis for a particular model is appropriate, too many statistical adjusting mechanisms and tests can be difficult to interpret and can lead to problems of multiple comparisons. ${ }^{19}$ Furthermore, the goal of propensity matching is to create similar groups, comparing apples with apples rather than apples with oranges. In this study, the propensity-matched patients were more like the RA group than the BITA group, so external validity for the greater BITA cohort is in question.

Although there is growing evidence supporting the use of arterial grafting, this strategy has yet to be adopted as mainstream practice by cardiac surgeons; in the United States, slightly more than $5 \%$ of patients undergoing CABG receive a second arterial graft. ${ }^{20}$ Recently, a study published by Gaudino and coworkers ${ }^{20}$ commented that grafting strategies are more of "an art than science" and provided an algorithm for graft selection for the second target vessel. In the pursuit of less art and more science, ${ }^{20}$ Pevni and colleagues ${ }^{1}$ should be commended for undertaking such a study of arterial revascularization. Although this study further adds to the conflicting evidence as to whether RITA is better than RA, what is evident in the literature is that a second arterial graft is important ${ }^{5}$; perhaps the type of arterial conduit is less of a factor. To this end, the multidisciplinary heart team can play an important role not only in patient selection ${ }^{21}$ but also in providing guidance regarding the type of grafting strategy that would be optimal for the individual patient.

\section{References}

1. Pevni D, Mohr R, Paz Y, Kramer A, Ben-Gal Y, Nesher N, et al. Outcome of revascularization with composite $\mathrm{T}$ grafts: Is bilateral thoracic grafting better than single thoracic and radial artery? J Thorac Cardiovasc Surg. 2016;151: 1311-9.

2. Deb S, Cohen EA, Singh SK, Une D, Laupacis A, Fremes SE, RAPS Investigators. Radial artery and saphenous vein patency more than 5 years after coronary artery bypass surgery: results from RAPS (Radial Artery Patency Study). J Am Coll Cardiol. 2012;60:28-35

3. Buxton BF, Shi WY, Tatoulis J, Fuller JA, Rosalion A, Hayward PA. Total arteria revascularization with internal thoracic and radial artery grafts in triple-vessel coronary artery disease is associated with improved survival. J Thorac Cardiovasc Surg. 2014;148:1238-43; discussion 1243-4.

4. Raza S, Sabik JF III, Masabni K, Ainkaran P, Lytle BW, Blackstone EH. Surgical revascularization techniques that minimize surgical risk and maximize late survival after coronary artery bypass grafting in patients with diabetes mellitus. $J$ Thorac Cardiovasc Surg. 2014;148:1257-64; discussion 1264-6.

5. Aldea GS, Bakaeen F, Pal J, Fremes S, Head SJ, Sabik J, et al. The Society of Thoracic Surgeons clinical practice guidelines on arterial conduits for coronary artery bypass grafting. Ann Thorac Surg. 2016;101:801-9.

6. Caputo M, Reeves B, Marchetto G, Mahesh B, Lim K, Angelini GD. Radial versus right internal thoracic artery as a second arterial conduit for coronary surgery: early and midterm outcomes. J Thorac Cardiovasc Surg. 2003;126:39-47.

7. Ruttmann E, Fischler N, Sakic A, Chevtchik O, Alber H, Schistek R, et al. Second internal thoracic artery versus radial artery in coronary artery bypass grafting: a long-term, propensity score-matched follow-up study. Circulation. 2011; 124:1321-9.

8. Schwann TA, Hashim SW, Badour S, Obeid M, Engoren M, Tranbaugh RF, et al Equipoise between radial artery and right internal thoracic artery as the second arterial conduit in left internal thoracic artery-based coronary artery bypass graft surgery: a multi-institutional study $\dagger$. Eur J Cardiothorac Surg. 2016;49:188-95

9. Shi WY, Hayward PA, Tatoulis J, Rosalion A, Newcomb AE, Fuller JA, et al. Are all forms of total arterial revascularization equal? A comparison of single versus bilateral internal thoracic artery grafting strategies. J Thorac Cardiovasc Surg. 2015; 150:1526-34.e3.

10. Gaudino M, Cellini C, Pragliola C, Trani C, Burzotta F, Schiavoni G, et al. Arterial versus venous bypass grafts in patients with in-stent restenosis. Circulation 2005;112(9 Suppl):I265-9.

11. Hayward PA, Buxton BF. Mid-term results of the Radial Artery Patency and Clinical Outcomes randomized trial. Ann Cardiothorac Surg. 2013;2:458-66.

12. Yuan SM, Shinfeld A, Raanani E. Configurations and classifications of composite arterial grafts in coronary bypass surgery. J Cardiovasc Med (Hagerstown). 2008;9:3-14.

13. Glineur D, Boodhwani M, Poncelet A, De Kerchove L, Etienne PY, Noirhomme P, et al. Comparison of fractional flow reserve of composite Y-grafts with saphenous vein or right internal thoracic arteries. J Thorac Cardiovasc Surg. 2010;140:639-45.

14. Kim KB, Hwang HY, Hahn S, Kim JS, Oh SJ. A randomized comparison of the Saphenous Vein Versus Right Internal Thoracic Artery as a Y-Composite Graft (SAVE RITA) trial: one-year angiographic results and mid-term clinical outcomes. J Thorac Cardiovasc Surg. 2014;148:901-7; discussion 907-8.

15. Glineur D, Hanet C, D'Hoore W, Poncelet A, De Kerchove L, Etienne PY, et al Causes of non-functioning right internal mammary used in a Y-graft 
configuration: insight from a 6-month systematic angiographic trial. Eur J Cardiothorac Surg. 2009;36:129-35; discussion 135-6.

16. Gaudino M, Alessandrini F, Pragliola C, Cellini C, Glieca F, Luciani N, et al. Effect of target artery location and severity of stenosis on mid-term patency of aorta-anastomosed vs. internal thoracic artery-anastomosed radial artery grafts. Eur J Cardiothorac Surg. 2004:25:424-8.

17. Deb S, Singh SK, Moussa F, Tsubota H, Une D, Kiss A, et al. The long-term impact of diabetes on graft patency after coronary artery bypass grafting surgery: a substudy of the multicenter Radial Artery Patency Study. J Thorac Cardiovasc Surg. 2014;148:1246-53; discussion 1253.
18. Deb S, Austin PC, Tu JV, Ko DT, Mazer CD, Kiss A, et al. A review of propensity-score methods and their use in cardiovascular research. Can J Cardiol. 2016;32:259-65.

19. Ludbrook J. Multiple comparison procedures updated. Clin Exp Pharmacol Physiol. 1998;25:1032-7.

20. Gaudino M, Taggart D, Suma H, Puskas JD, Crea F, Massetti M. The choice of conduits in coronary artery bypass surgery. J Am Coll Cardiol. 2015;66:1729-37.

21. Deb S, Wijeysundera HC, Ko DT, Tsubota H, Hill S, Fremes SE. Coronary artery bypass graft surgery vs percutaneous interventions in coronary revascularization: a systematic review. JAMA. 2013;310:2086-95.

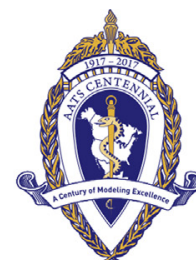

AMERICAN ASSOCIATION FOR THORACIC SURGERY A Century of Modeling Excellence

Countdown the AATS Centennial On this month in... 